Revista de Comunicación y Salud, 2020, Vol. 10, no 2, pp. 503-524

Editado por Cátedra de Comunicación y Salud

ISSN: 2173-1675

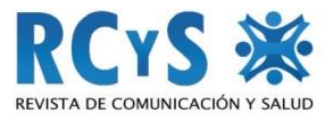

Enviado 25/04/2020

Aprobado 09/09/2020

\title{
EL CORONAVIRUS A TRAVÉS DE LOS TITULARES DE EL MUNDO Y LA VANGUARDIA
}

\author{
Marián Alonso-González'. \\ Universidad de Sevilla. España \\ malonsog@us.es
}

Coronavirus through EI Mundo and La Vanguardia's headlines

\section{Resumen}

El coronavirus se ha convertido en una pandemia que ha condenado al confinamiento a 3.000 millones de ciudadanos de todo el mundo. En España, el virus afecta a más de 200.000 personas y ha provocado la muerte de casi 23.000 , es por ello, que la presente investigación tiene por objeto realizar una reflexión sobre el papel de la prensa escrita durante la cobertura informativa del primer mes del Covid-19 en nuestro país. Para llevarla a cabo hemos realizado un análisis de los elementos de primera lectura, como son titulares y otros elementos que conforman el grupo de titulación, publicados en El Mundo y La Vanguardia, los dos diarios digitales con un mayor número de lectores. Partiendo de la hipótesis de que las informaciones relativas al nuevo virus son poco divulgativas y un tanto sensacionalistas, hemos recurrido al estudio de caso como método de investigación para analizar un total de 2.513 titulares publicados entre el 24 de febrero y el 24 de marzo. Pese a que en su mayoría son de índole informativo, se aprecia un estilo de redacción centrado en la expansión del virus, los fallecimientos y las repercusiones negativas que está teniendo en ámbitos tan alejados de la salud como son el económico, el cultural y el deportivo, por lo que hemos comprobado que los titulares de ambos diarios se centran en aspectos sensacionalistas en vez de intentar explicar a los ciudadanos lo que está sucediendo y promover un conocimiento que dé cuenta de la complejidad del fenómeno.

Palabras claves: Prensa digital, titulares, noticias, coronavirus, pandemia, salud, Covid-19

\begin{abstract}
The coronavirus has become a pandemic that has condemned more than 3.000 million people to confinement in the world. In Spain, the virus affects more than 200.000 persons and has caused the death of more than 22.000. The purpose of this
\end{abstract}

${ }_{1}^{1}$ Autor para correspondencia: Marián Alonso González malonsog@us.es 
investigation is to reflect the role of newspapers during the first month's news coverage of Covid-19 in our country. For this reason, we have carried out an analysis of the elements of first reading, such as headlines and other elements that make up the titling groups, published in El Mundo and La Vanguardia, the two digital newspapers that have the largest number of readers. Starting from the hypothesis that the information related to the new virus is not very informative and somewhat sensational, we have used the case study as a research method to analyze a total of 2.513 headlines published between February 24 and March 24. Despite the fact that most of the headlines are informative, there is a writing style focused on the spread of the virus, deaths and the negative repercussions it is having in areas as far removed from health as economic, cultural and sports. So both newspapers focus on sensational aspects instead of trying to explain what is happening to citizens and explain the complexity of the phenomenon.

Keywords: Digital media, headlines, news, coronavirus, pandemic, health, Covid-19

\section{Cómo citar el artículo}

Alonso-González, M. (2020). El coronavirus a través de los titulares de El Mundo y La Vanguardia. Revista de Comunicación y Salud, 10 (2), 503-524. doi: https://doi.org/10.35669/rcys.2020.10(2).503-524

\section{INTRODUCCIÓN}

El coronavirus o Covid-19 es una enfermedad infecciosa causada por un nuevo virus detectado en los humanos a finales de diciembre 2019. Los primeros casos se dieron en China, concretamente en la ciudad de Wuhan, y aunque en un principio se pensó que el foco estaba en un mercado de marisco y pescado de dicha localidad, investigaciones llevadas a cabo por la Academia de la Ciencia de China lo ha descartado y siguen barajando la idea que el virus mutara en algún animal antes de pasar al ser humano.

Hasta el momento se conocen siete virus de la familia de los coronavirus, incluido el SARS-CoV-2, que han saltado de animales a humanos y han sido responsables de "los brotes de enfermedades más destructivas de la historia, como son las pandemias de la gripe de 1918, 1957, 1968, y los brotes de SARS ${ }^{2}$, MERS ${ }^{3}$ y ébola" (Navas, 2020).

Los coronavirus tienen ese nombre por las proteínas espiga que sobresalen de su superficie, y estas espigas son las que se adhieren a la célula para entrar a ella. Una vez dentro, utiliza la maquinaria de la célula como una fábrica para hacer copias de sí mismo y de su material genético. La característica crucial del Covid-19 reside en que puede alojarse tanto en el tracto respiratorio superior, propagándose con la tos, como en el inferior, provocando enfermedades en los pulmones.

2 Síndrome Respiratorio Agudo Severo

3 Síndrome Respiratorio de Oriente Medio 
La nueva pandemia, como la ha definido la Organización Mundial de la Salud, se propaga principalmente de persona a persona, sobre todo mediante las gotículas respiratorias que se producen cuando una persona infectada tose o estornuda. Estas gotas con el virus se pueden depositar en diferentes superficies y objetos, donde es capaz de sobrevivir hasta 36 horas, por lo que es potencialmente infeccioso si cualquier persona que haya entrado en contacto con él se toca la boca, nariz y los ojos.

Según el Ministerio de Sanidad (MSCBS, 2020), la permanencia del SARS-CoV-2 es viable en superficies de cobre, cartón, acero inoxidable y plástico de 4, 24, 48 y 72 horas, respectivamente, cuando se mantiene a $23^{\circ} \mathrm{C}$ y con un $40 \%$ de humedad relativa. Ello favorece que pueda transmitirse con gran facilidad. A todo ello, además, hay que sumar el hecho de que una persona contagiada, y potencialmente transmisora, puede no presentar síntomas durante quince días. Asimismo, una vez superada la enfermedad, durante la fase de excreción del virus, que tiene una duración media de 20 días, los pacientes aún son capaces de propagarlo.

Con una tasa de letalidad del 3,7\% (OMS, 2020), el coronavirus se ha extendido con gran rapidez por todo el planeta, de manera que, cinco meses después de su aparición, el nuevo virus ya ha afectado a más de tres millones de personas, de las cuales más de 170.000 han fallecido.

Entre las principales medidas para evitar la propagación del virus se encuentra la correcta higiene de las manos con agua y jabón o con desinfectante a base de alcohol, cubrirse la nariz y la boca al toser o estornudar con un pañuelo de papel desechable 0 con la parte interna del codo, así como evitar el contado directo con el resto de las personas, lo que implica mantener al menos un metro de distancia con respecto a las mismas.

Según el Ministerio de Sanidad, los coronavirus humanos "se inactivan de forma eficiente en presencia de etanol al $95 \%$ o de hipoclorito sódico en concentraciones de 0,1\%" (MSCBS, 2020:4), por lo que la higiene se convierte en un elemento imprescindible para luchar contra la enfermedad. Sin embargo, por sí sola esta medida ha resultado ineficiente, lo que ha llevado a la Organización Mundial de la Salud a declarar la emergencia sanitaria internacional ${ }^{4}$ con objeto de aumentar la coordinación entre las redes sanitarias mundiales y homogeneizar programas de prevención, tratamiento, cuarentena y concienciación.

Con un riesgo por expansión "muy alto", los Gobiernos han tenido que tomar medidas drásticas para contener su propagación y son muchos los países que han optado por el cierre de fronteras y el confinamiento de sus ciudadanos en sus hogares, lo que está generando graves repercusiones a nivel económico y social.

4 Para declarar la emergencia internacional, la OMS exige tres criterios: que se trate de un evento extraordinario, que constituya un riesgo de rápida expansión en otros países y que requiera una respuesta coordinada internacional. 
En España, y en base al artículo 116 de la Constitución, el Gobierno decretó el Estado de alarma el 14 de marzo, con el fin de garantizar la protección de la salud de los ciudadanos, la contención de la enfermedad y el refuerzo del sistema de salud pública. Durante un periodo de 15 días se ordenó a la población permanecer en sus hogares, pudiéndose circular, de manera individual, para realizar actividades de primera necesidad, tales como compra de alimentos o medicamentos, asistencia a centros sanitarios o entidades financieras, retorno a la residencia habitual, asistencia a personas vulnerables y desplazamientos al lugar de trabajo.

La nueva situación ha provocado que las grandes empresas hayan respondido con rapidez a la crisis extendiendo el trabajo desde casa, de manera que el teletrabajo, que según datos del INE (2019) en nuestro país sólo alcanzaba al 7\% de los ocupados $(1,4$ millones de personas), roza en la actualidad "el $65 \%$ de los 19,7 millones de ocupados que han seguido trabajando tras el decreto del estado de alarma" (Peña, 2020). Ello es posible gracias a que España es el tercer país de Europa en conexiones de fibra, lo que supone el $65 \%$ de las conexiones de banda ancha fija, y las redes móviles $4 \mathrm{G}$ ofrecen cobertura hasta el 99\% de la población (Lafraya, 2020).

Trascurrida la quincena inicial prevista por el Gobierno, el Congreso de los Diputados daba su aval para prorrogar la situación hasta el 12 de abril y se endurecían las condiciones del aislamiento, optándose por paralizar toda la actividad económica, salvo aquellas actividades definidas como imprescindibles, a fin de limitar, aún más, el contacto social, la movilidad y descongestionar las Unidades de Cuidados Intensivos de los centros sanitarios.

Tras dos nuevas prórrogas, menos restrictivas, y con fecha de finalización prevista de 9 de mayo, el Gobierno de España ha anunciado que la "desescalada" comenzará tímidamente a partir del 27 de abril, día en que se dejará salir de casa a los menores de 14 años, aunque las salidas "estarán limitadas y sujetas a condiciones para limitar los contagios" (Cué, 2020).

\subsection{Titulares de prensa para conocer la actualidad informativa}

El coronavirus ha trascendido el ámbito de la salud y está afectando a nuestra vida cotidiana en todos sus órdenes, es por ello que el presente estudio tiene por objeto analizar los titulares que sobre esta pandemia han publicado El Mundo y $\mathrm{La}$ Vanguardia.

La elección de los titulares como objeto de análisis para esta investigación responde a la necesidad de explorar el discurso periodístico de esta crisis sanitaria a través de un texto complejo. El titular, como primer estrato de la noticia, se convierte en su más "sintético representante, al tiempo que la singulariza y asume, separándola del resto de los contenidos del periódico" (Ruiz Acosta, 1992:82). Estos "textos autónomos" (Zorrilla Barroso, 1996) tienen la misión de llamar la atención de los lectores para que lean los 
textos informativos que le siguen, e incluso, para que paguen por servicios de suscripción, un modelo de negocio centrado en el pago de contenidos de calidad.

Los titulares se configuran como la parte de la noticia con un mayor impacto en la audiencia, "principalmente por la tendencia de una parte importante de los lectores a prestar atención sólo a la cabeza de titulación de una información" (López y Túñez, 1995). De hecho, según el estudio Digital News Report (Amoedo, 2019), los internautas solo leen los titulares de las noticias de los medios de comunicación, lo cual les permite conocer la actualidad del momento de forma superficial.

En España, según el Libro Blanco de la Información (AMI, 2017), el 49,3\% de los lectores en papel sólo lee titulares y consume ciertas noticias de interés. En el ámbito digital este porcentaje llega al $57,1 \%$, y al $63,7 \%$ para aquellos que acceden a la información a través de las redes sociales.

En el modelo de cultura vigente, el consumo de información a través de los smartphones se ha convertido en la primera opción de lectura, de hecho, según un estudio publicado por la Asociación para la Investigación de Medios de Comunicación (AIMC, 2019), el 68,4\% de los internautas españoles utilizan el teléfono móvil para leer el diario, frente a los que usan el portátil $(51,6 \%)$. Este cambio en las costumbres ha motivado que los medios escritos "se hayan visto en la obligación de adaptar el consumo de sus productos informativos a los nuevos dispositivos tecnológicos y a los nuevos canales de acceso y distribución de la información" (Benaissa, 2019).

La aceleración del ritmo de producción de noticias y la reducción de los tiempos de lectura en los dispositivos electrónicos ha provocado que los titulares de prensa se hayan convertido en el principal modo de conocer la actualidad informativa y, prueba de ello, es que desde el año 2000 "todos los grandes diarios españoles con edición digital han introducido los servicios gratuitos de titulares a través del correo electrónico" (Pou, 2000).

La labor de titulación es uno de los niveles del gatekeeping, o proceso de reconstrucción que cada diario hace de la realidad, y es resultado de un procedimiento de inclusiones y exclusiones, "capaz de definir por sí mismo la tendencia ideológica de un medio de comunicación" (Oliva, 2011).

Puesto que la función básica y principal que desempeña el titular de prensa es la de mostrar o anunciar la esencia de la noticia, resulta de especial interés reflexionar sobre la calidad informativa en la titulación aplicada a las informaciones publicadas en los diarios digitales sobre el coronavirus y comprobar si, como afirma Fontcuberta, "el objetivo del titular de la noticia periodística es la de anunciar, atraer y sintetizar" (1996:117), tres cualidades que consiguen hacer de este elemento la referencia informativa de todo lo que ocurre en el mundo.

\section{OBJETIVO E HIPÓTESIS}


La presente investigación tiene por objeto conocer el tratamiento informativo que $E l$ Mundo y La Vanguardia están otorgando al coronavirus. Para ello, vamos a analizar los titulares de las noticias que ambos diarios han publicado sobre esta pandemia para, a través de diferentes variables y categorías, conocer si la prensa juega un papel divulgativo, preventivo y/o de concienciación.

Como objetivo secundario, nos marcamos el estudio del resto de elementos que conforman el grupo de titulación y otros elementos de primera lectura, como pueden ser las imágenes, vídeos o mapas, a fin de realizar una compleja reflexión sobre el papel de la prensa durante la cobertura del primer mes del Covid-19 en España, y, de esta forma, poder concretar si se ha producido un tratamiento alarmista y sensacionalista en dichas informaciones.

En el diseño de la investigación, hemos partido de las siguientes hipótesis:

H1. Los medios de comunicación no realizan una gran labor de prevención y/o concienciación.

H2. Las informaciones relacionadas con el coronavirus están cargadas de sensacionalismo y son poco divulgativas, tal y como debería esperarse.

\section{METODOLOGÍA}

Para la consecución del objetivo marcado hemos recurrido al estudio de caso como método de investigación social por su gran relevancia para el desarrollo de las ciencias humanas y sociales, pues implica un proceso de indagación, caracterizado por el examen sistemático y en profundidad de casos particulares (Barrio et al., 2010).

La particularidad más característica de ese método es el estudio intensivo y profundo de un/os caso/s, entendiendo éste como un "sistema acotado" por los límites que precisa el objeto de estudio, pero enmarcado en el contexto global donde se produce, lo cual permitiría, según Thomas (2011), probar procedimientos, identificar problemas y seleccionar variables e instrumentos de medición pertinentes al estudio.

Con objeto de obtener una acumulación estructurada de datos que nos facilite la extracción de inferencias de interés para los objetivos de esta investigación, hemos completado nuestro estudio con un enfoque cuantitativo, optando por una perspectiva metodológica mixta, la cual nos permite la utilización de estadísticas y la medición de determinados fenómenos, propios de lo cuantitativo, con la exploración en profundidad de la problemática examinada y la extracción y comprensión de los significados vinculados las mismas, característico de lo cualitativo.

Para llevar a cabo esta investigación hemos realizado un estudio de los titulares publicados por El Mundo y La Vanguardia en su edición digital. La elección responde a que ambos son los diarios más consultados en España a través de internet y de las redes sociales según comScore (PRnoticias, 2019), quien recoge que 21,4 millones de usuarios accedieron en diciembre de 2019 a la web del Grupo Godó mediante sus 
dispositivos móviles, 300.000 usuarios más que los lectores que optaron por elmundo.es, que se encuentra en segunda posición.

El periodo de estudio abarca desde el 24 de febrero, día en el que los medios registran el primer posible positivo de coronavirus en España ${ }^{5}$, hasta el 24 de marzo de 2020, a fin de que los datos obtenidos fueran de actualidad y valorar el impacto que ha generado en su contexto, ya que se trata de un periodo suficiente para poder desarrollar un correcto estudio longitudinal.

En total, hemos analizado 2.513 titulares, los cuales han sido categorizados mediante una ficha que recoge los siguientes parámetros:

1. Identificación del número de noticias diarias publicadas.

2. Ubicación. Portada o páginas interiores, así como la sección en la que se encuentra.

3. Longitud. Titulares a una, dos, tres, cuatro o cinco columnas.

4. Presencia de antetítulos y cintillos

5. Presencia de fotografías, vídeos, mapas o infografías.

6. Identificación de la fuente de la noticia (firma, redacción, agencia, enviado especial o corresponsal).

7. Clasificación de los titulares en base a las tres grandes tipologías identificadas por Núñez Ladeveze (1991:221):

- Informativo. Identifica una unidad de acción en el espacio tiempo.

- Apelativo. Utiliza el lenguaje para llamar la atención sobre un hecho del que no se informa porque su conocimiento se presume.

- Expresivo. No aporta información sobre los hechos, sino que enuncia el tema de la información sin permitir identificar la noticia.

A esta triple clasificación añadimos dos más, los titulares opinativos y los de cita.

- Opinativos. Aportan una interpretación valorativa de lo dicho, de manera que se trata de un titular más próximo a la opinión que a la información, pues aporta un valor añadido (Mediavilla, 2010).

- Cita. Aquellos que "seleccionan una frase del discurso como representación del sentido del acto de habla" (Zorrilla, 2002:145).

8. Identificación del tipo de discurso informativo. Para ello, comprobaremos la frecuencia en la que los titulares son de tipo enunciativo y, por ende, responden al esquema de Sujeto + Verbo + Predicado, o bien, poseen una estructura de frase nominal, aquella que está formada por un núcleo al que pueden acompañar un determinante 0 un adyacente.

9. Identificación de los tiempos verbales más utilizados y si se usan en voz activa o pasiva.

10.Siguiendo la metodología expuesta por Costa-Sánchez (2011) reseñaremos la presencia de palabras susceptibles de generar alarma en la población, como

${ }^{5}$ Fecha en la que el virus saltó a la península, detectándose los primeros casos en la Comunidad de Madrid, Cataluña y la Comunidad Valenciana. El primer paciente registrado en España fue un turista alemán que tuvo que ser ingresado en La Gomera el 31 de enero. 
son: epidemia, pandemia, alerta, emergencia, alarma, cuarentena, peor (malo/grave), crisis/caos, pánico (miedo/temor), confinamiento/aislamiento, amenaza, contagio/infección, riesgo/peligro, muertos, apocalíptico.

11. Tema abordado. Para ello hemos propuesto las siguientes categorías:

- Contagios, evolución e historias de contagiados.

- Fallecimientos.

- Altas médicas.

- Vacunas, tratamientos y avances científicos.

- Estado de la situación.

- Mensajes de tranquilidad.

- Comunicaciones oficiales (Gobierno y CC.AA.).

- Confinamiento, cuarentena y medidas preventivas.

- Estado de Alarma.

- Explicación del funcionamiento del virus.

- Cierre de fronteras.

- Consecuencias económicas, sociales / culturales, deportivas y laborales.

- Entrevistas.

- Mapas.

- Otros.

12. Identificación de los valores noticiosos que predominan en los titulares de salud en base a la propuesta de Díaz Rojo (2009), basándose en la teoría de Galtung y Ruge (1965) y estudios posteriores; y que se adaptan al nuevo contexto mediático de la Web 2.0: continuidad, curiosidad, celebridades, desviación, drama personal, entretenimiento, impacto social, magnitud, naciones élites, negatividad, novedad, poder, polémica, positividad, proximidad geográfica o cultural, relevancia, sorpresa, utilidad y valor educativo.

\section{ANÁLISIS Y DISCUSIÓN}

A lo largo del presente estudio hemos analizado un total de 2.513 titulares, de los cuales, 1.254 han sido publicados en El Mundo y 1.259 en La Vanguardia.

El número de noticias diarias ha ido creciendo de forma proporcional a las dimensiones de esta pandemia. Si durante los dos primeros días entre ambos diarios sólo publicaron 15 titulares, esta cantidad se multiplicó por ocho durante la primera quincena de marzo. De hecho, el 12 de marzo, día que el Gobierno anuncia que se decretará el Estado de Alarma, entre ambos diarios publican 129 titulares (64 y 65, respectivamente).

El incremento de contagios, fallecimientos y un confinamiento que afecta a todas las áreas de nuestra vida ha hecho que entre el 15 y el 24 de marzo se hayan publicado la mitad de los titulares de este estudio, tal y como puede apreciarse en el siguiente gráfico. 


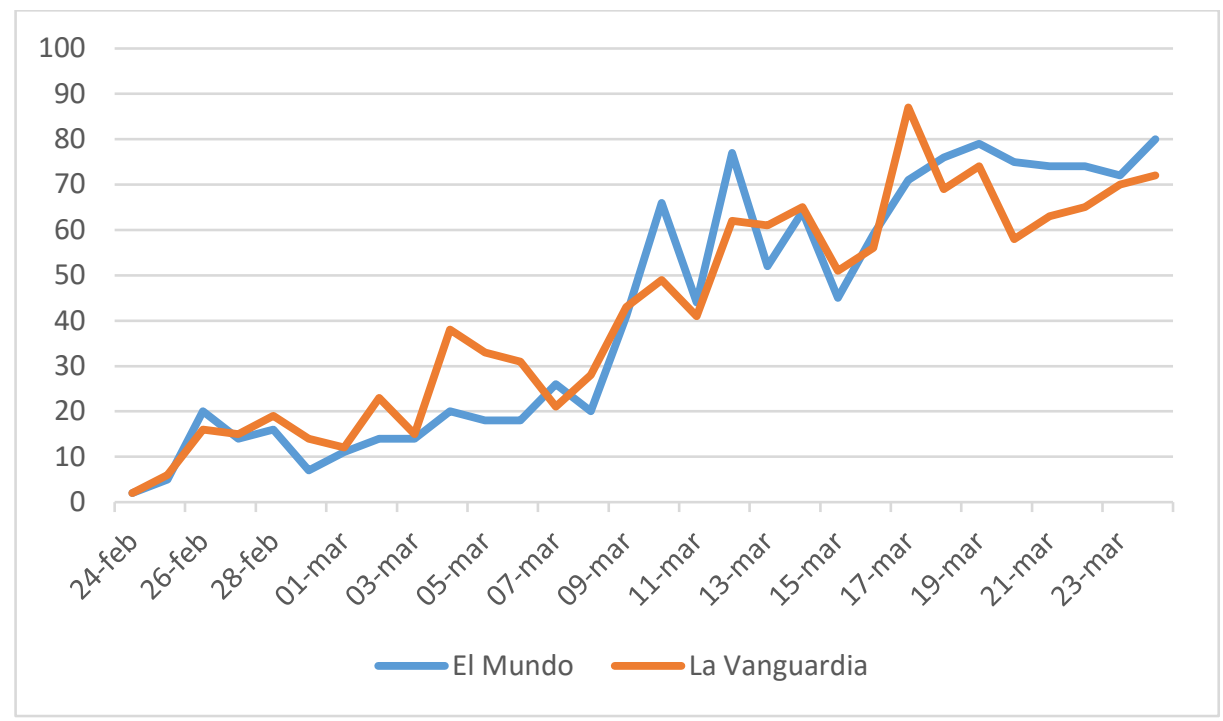

Gráfico 1. Noticias publicadas por El Mundo y La Vanguardia (24/02 a 24/03) Fuente: elaboración propia

\subsection{Ubicación de los titulares por secciones}

El $73 \%$ de los titulares analizados en El Mundo se encontraba en las secciones de Internacional (14\%), Portada (13\%), Nacional (12\%), Economía (11\%) y Salud (10\%). Esto nos da una idea del alcance global que el coronavirus tiene en todas las áreas de nuestra vida y de la importancia informativa del tema, que llega a copar el total de las informaciones de Portada y la actualidad de secciones como Internacional o Economía, antes que la propia de Salud (Ver Gráfico 2).

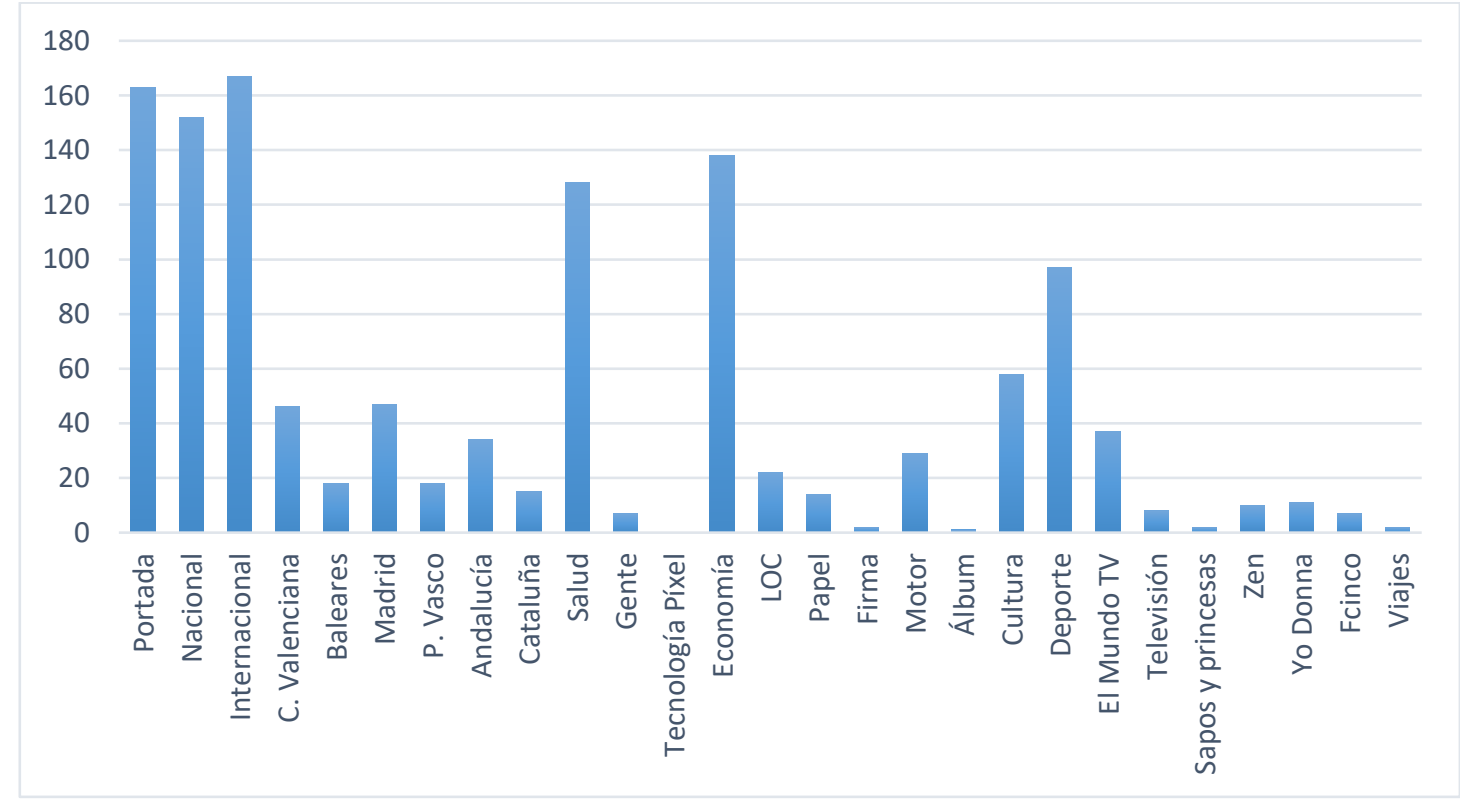

Gráfico 2. Noticias publicadas por secciones en El Mundo

Fuente: elaboración propia

Revista de Comunicación y Salud, 2020, Vol. 10, № 2, pp. 503-524 
Un fenómeno similar se observa en La Vanguardia, el 63\% de los titulares analizados se ubica en esas mismas 5 secciones: Vida (20\%), Portada (14\%) Internacional (10\%), Economía (10\%) y Política (9\%) (Ver Gráfico 3). Sin embargo, el rotativo del Grupo Godó otorga prioridad a la sección de Vida, que alberga las noticias de Ciencia y Salud, y que responde al interés de este periódico por dicho ámbito. La Vanguardia fue el primer periódico que insertó "cuatro páginas monográficas dedicadas a la divulgación de las ciencias y de la medicina" (Alonso-González, 2018:57) y que fueron las precursoras de los diversos suplementos de Ciencias, Medicina y Salud que han llegado hasta nuestros días.

Otro aspecto a señalar es el peso que poseen las informaciones deportivas. El 8\% de las noticias de El Mundo y un 7\% de las publicadas por La Vanguardia se encuadran dentro de esta sección que, si bien temáticamente se encuentra muy alejada del asunto de nuestro estudio, se ha visto gravemente perjudicada por el virus, el cual ha provocado que se suspendan todas las disciplinas deportivas, ERTEs en las plantillas futbolísticas e, incluso, la cancelación de los Juegos Olímpicos de Tokio 2020, una circunstancia que sólo se había producido cuatro veces con anterioridad y debido a la coyuntura histórica de la I y II Guerra Mundial (Berlín 1916, Tokio/Helsinki 1940 y Londres 1944).

La información local también posee un peso específico dentro del conjunto de titulares analizados en ambos periódicos, de hecho, El Mundo ha publicado 178, lo que supone un $14 \%$ de sus noticias, y La Vanguardia 166, un 13\%. Curiosamente, estas informaciones se circunscriben en ambos diarios a las Comunidades Autónomas de Andalucía, Madrid, Cataluña, País Vasco y Comunidad Valenciana. Las noticias relativas a otras comunidades resultan muy escasas y se integran en las secciones de Nacional y Política, respectivamente.

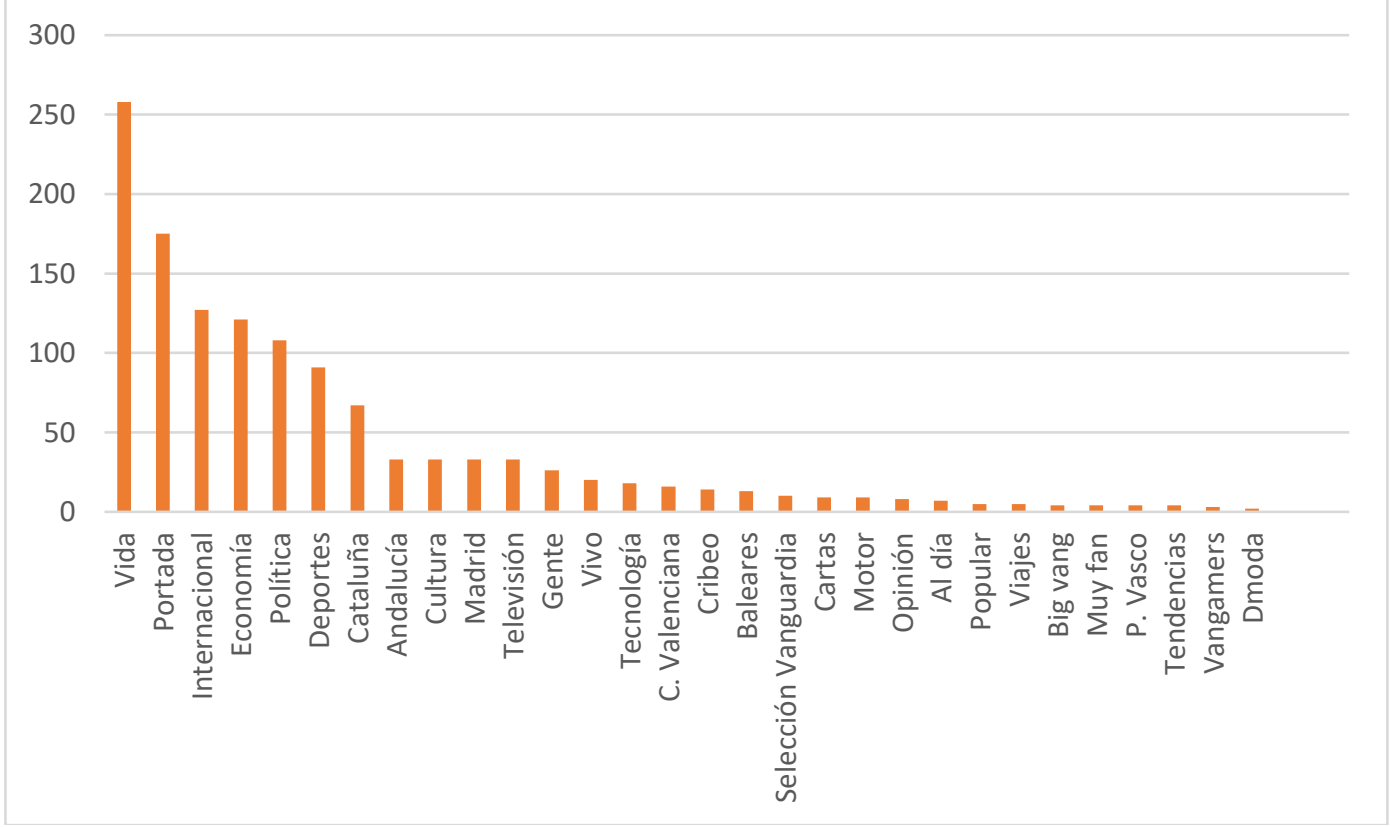

Gráfico 3. Noticias publicadas por secciones en La Vanguardia Fuente: elaboración propia

Revista de Comunicación y Salud, 2020, Vol. 10, oㅡ 2, pp. 503-524 
En total, los 1.254 titulares analizados en El Mundo han sido publicados en 26 secciones diferentes, y los 1.259 de La Vanguardia en 30, algunas tan variopintas como Tecnología, Viajes y Gente, lo cual es un claro reflejo de cómo el coronavirus afecta a todos los órdenes de nuestra vida, desde la forma en la que nos relacionamos con los demás, a nuevas formas de trabajo o de entretenimiento.

\subsection{Tipología y tamaño de los titulares}

El 74\% de los titulares aparecidos en El Mundo es de impacto medio ( 3 columnas), seguido por los de un alto impacto (4 y 5 columnas) en el $14 \%$ de los casos, mientras que los de bajo impacto ( 1 y 2 columnas) fueron un $12 \%$. En el caso de La Vanguardia, predominan los titulares de alto impacto (76\%), seguido de los de impacto medio (16\%) y los de bajo impacto (8\%).

Por tipología, el $75 \%$ de los titulares es informativo, mientras que el $25 \%$ restante se distribuye entre temáticos, apelativos, opinativos y de cita. Por diarios, los informativos son más abundantes en La Vanguardia, hasta un total de 991, mientras que los de cita son más abundantes en El Mundo (237), tal y como puede apreciarse en el Gráfico 4.

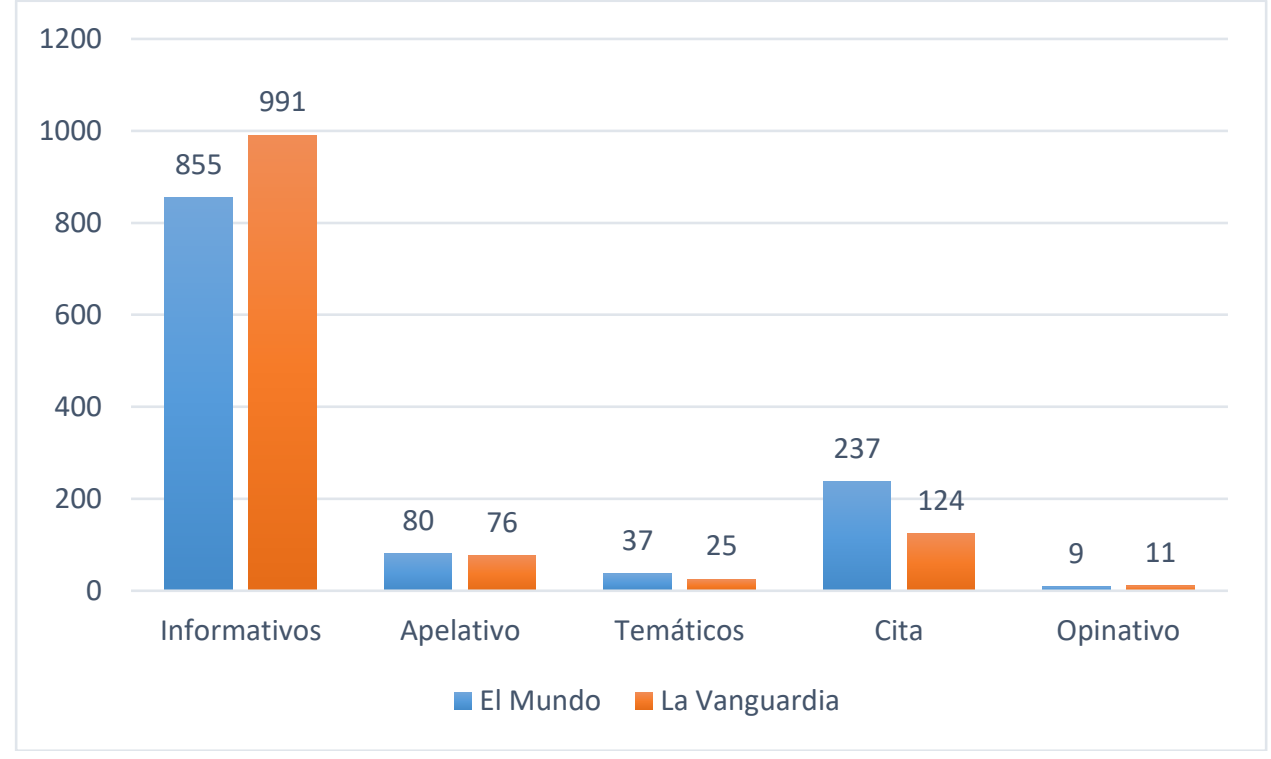

Gráfico 4. Tipología de los titulares

Fuente: elaboración propia

Aunque la presencia de titulares informativos es mayoritaria se aprecia un estilo de redacción centrado en la expansión del virus y sus consecuencias, alejándose, por tanto, de lo divulgativo para centrarse en el coronavirus como protagonista de todas las áreas mediante un estilo de redacción que roza lo sensacionalista.

Esta misma idea queda reforzada tras el estudio del tamaño de los titulares, ya que ambos diarios buscan atraer la atención del lector con titulares llamativos, presentando de un vistazo los hechos más relevantes de la jornada, lo que nos da idea de la trascendencia informativa que para ambos medios tiene el coronavirus (Armentia y 
Caminos, 1998:199), al tiempo que evidencia la sobreinformación que sobre este asunto estamos teniendo.

Respecto a la estructura sintáctica, la mayor parte de los titulares se atiene a la fórmula de Sujeto + Verbo + Complemento. Esta estructura lógica es usada en el $74 \%$ de las ocasiones por El Mundo y en el $80 \%$ en La Vanguardia, el resto, como puede apreciarse en el Gráfico 5, o bien arranca el titular con un participio porque no hay sujeto ( $11 \%$ y $7 \%$, respectivamente), o el mismo está implícito y no aporta nada (15\% y $13 \%)$.

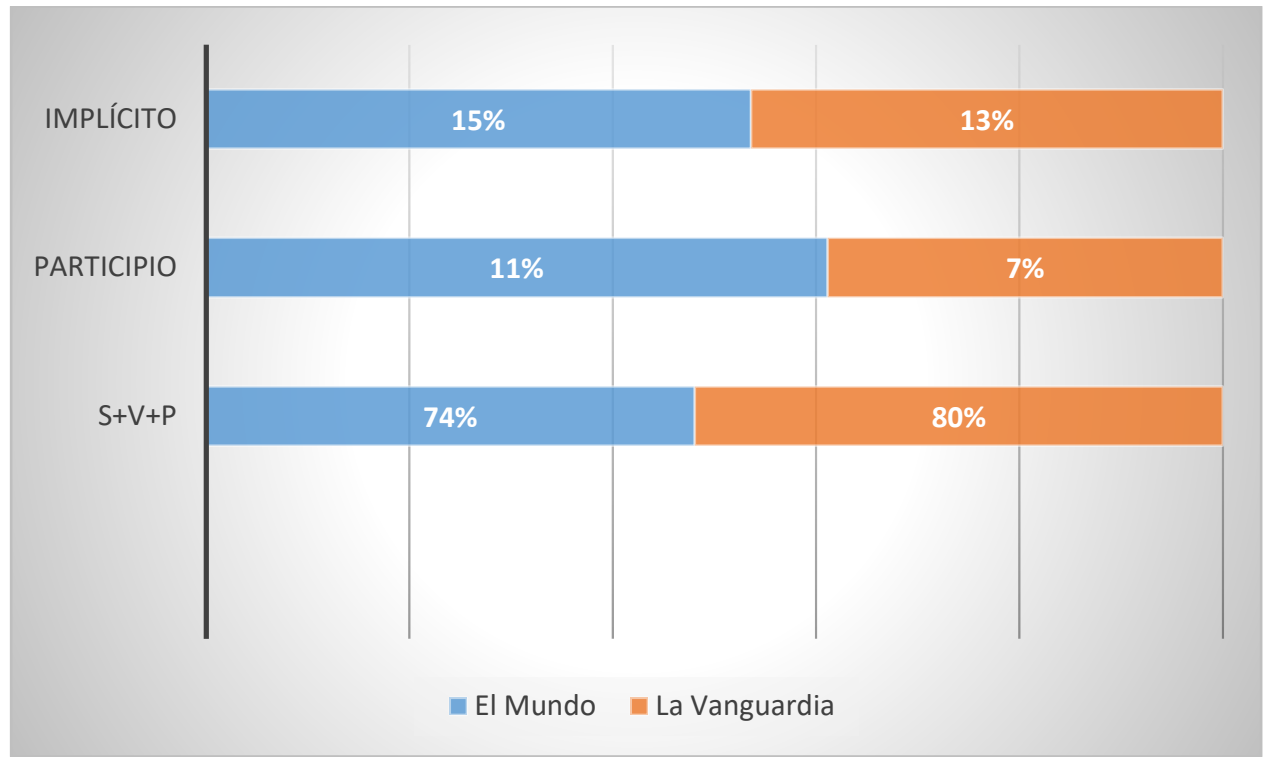

Gráfico 5. Estructura sintáctica de los titulares

Fuente: elaboración propia

Aunque la mayoría de las noticias se escriben en pasado porque se refieren a hechos ya concluidos, el $85 \%$ de los tiempos verbales usados por ambos diarios está en presente de indicativo, el cual es multifuncional, ya que presenta como actuales tanto los hechos pasados como los futuros, al tiempo que es más breve a la hora de afrontar un titular. En menor medida se utiliza el infinitivo (El Mundo 7\% y $\mathrm{La}$ Vanguardia 6\%), cuyo uso mayoritariamente se circunscribe a los titulares opinativos.

Otros tiempos verbales usados de forma residual son el pasado $(3 \%$ y $2 \%$, respectivamente) y el futuro (5\% y $7 \%$ ), el cual se emplea fundamentalmente en los titulares de cita y para anunciar determinados hechos que con casi absoluta certeza se van a producir. No se ha detectado el uso del condicional, que podría transmitir imprecisión, ni construcciones verbales en negativo.

Respecto a la voz, la totalidad de titulares de ambos diarios se encuentra en activo, acatando la norma básica de redacción periodística de no utilizar la voz pasiva en la titulación. 
A partir del análisis gramatical es posible afirmar que los encuadres adoptados son muy similares en ambos periódicos y ofrecen un contexto interpretativo en el que destaca la presentación del coronavirus como un sujeto agente y no como paciente de otros agentes económicos, políticos y sociales, de forma que tanto El Mundo como La Vanguardia elaboran su discurso en torno a la crisis del coronavirus y a las consecuencias que está generando.

\subsection{Características del grupo de titulación}

Ambos periódicos realizan un uso correcto de la jerarquía de contenidos para orientar al usuario y, para ello, agrupan los elementos pertenecientes a una misma unidad informativa a fin de facilitar una lectura de doble velocidad, esto es, una primera lectura rápida de titulares, antetítulos y cintillos, y una lectura más reposada y en profundidad de las noticias.

Esta nueva pauta dentro del periodismo español ha estado encabezada por El Mundo, pionero en darle un nuevo rumbo al diseño periodístico, otorgando gran importancia al grupo de titulación y a la presencia de fotografías de gran tamaño a fin de agilizar la lectura del texto.

El $80 \%$ de los titulares de El Mundo incorpora cintillo y el 14\% antetítulo. En el caso de $\mathrm{La}$ Vanguardia, el antetítulo aparece en el $9,4 \%$ de las ocasiones y el cintillo en el $77,2 \%$ de los titulares.

Respecto a la autoría de los textos y su vinculación profesional con el medio en que publican, comentar que el $79 \%$ de las noticias de El Mundo van firmadas, de ellas, el $68 \%$ responde a un profesional en plantilla y el $11 \%$ a enviados especiales 0 corresponsales. El resto se reparte entre un $9 \%$ de noticias procedentes de agencias, el $10 \%$ textos elaborados por la redacción y un $2 \%$ sin firma.

Al igual que en El Mundo, sólo un 2\% de las noticias publicadas por La Vanguardia carece de firma. No obstante, las pertenecientes a personal de plantilla es el $61 \%$, de ellas, el $9 \%$ corresponde a enviados especiales y corresponsales. De igual forma, el $15 \%$ de las informaciones vienen firmadas por una agencia y el $22 \%$ por la redacción.

La vinculación profesional del periodista que firma la noticia presenta una relación directa con la mayor o menor originalidad del tema tratado. Así, mientras que existe una homogeneidad temática en el $90 \%$ de las noticias procedentes de agencias y de redacción, las firmadas por periodistas de la casa, enviados especiales y corresponsales presentan un alto grado de originalidad, lo que otorga exclusividad informativa al medio que lo publica.

En este sentido, las noticias de El Mundo resultan más completas y complejas que las publicadas por La Vanguardia, el cual se nutre en mayor medida de informaciones procedentes de agencias de prensa y comunicaciones oficiales. 
En la era de la post-modernidad, lo visual persuade al lector tanto o más que un buen titular sugerente (Imbert, 1999), por lo que los "aspectos fotográficos, así como, gráficos e infográficos (dada la primacía de lo visual a lo textual)" acrecientan "el grado de comprensión de las noticias para los lectores” Fernández-Gil (2010:138).

En este sentido, los elementos icónicos que acompañan a los titulares objeto de nuestro estudio, tal y como podemos apreciar en el Gráfico 6, son más numerosos y variados en El Mundo, que hace uso de las posibilidades multimedia que permite la Web 3.0 para incluir videonoticias y mapas interactivos que enriquecen los textos periodísticos y que sirven, además, de Centro de Impacto Visual de las informaciones.

Mientras que El Mundo ilustra el $94 \%$ de sus noticias sobre el coronavirus, La Vanguardia lo hace en el $87,3 \%$. De igual forma, el $90 \%$ de las imágenes analizadas en ambos periódicos presentan un alto impacto, ya que figuran a tres o cuatro columnas, sin embargo, El Mundo va más allá y, al menos en el $20 \%$ de las ocasiones, ofrece galerías de imágenes, lo que permite al medio interactuar de manera virtual con otras personas sobre una misma noticia.

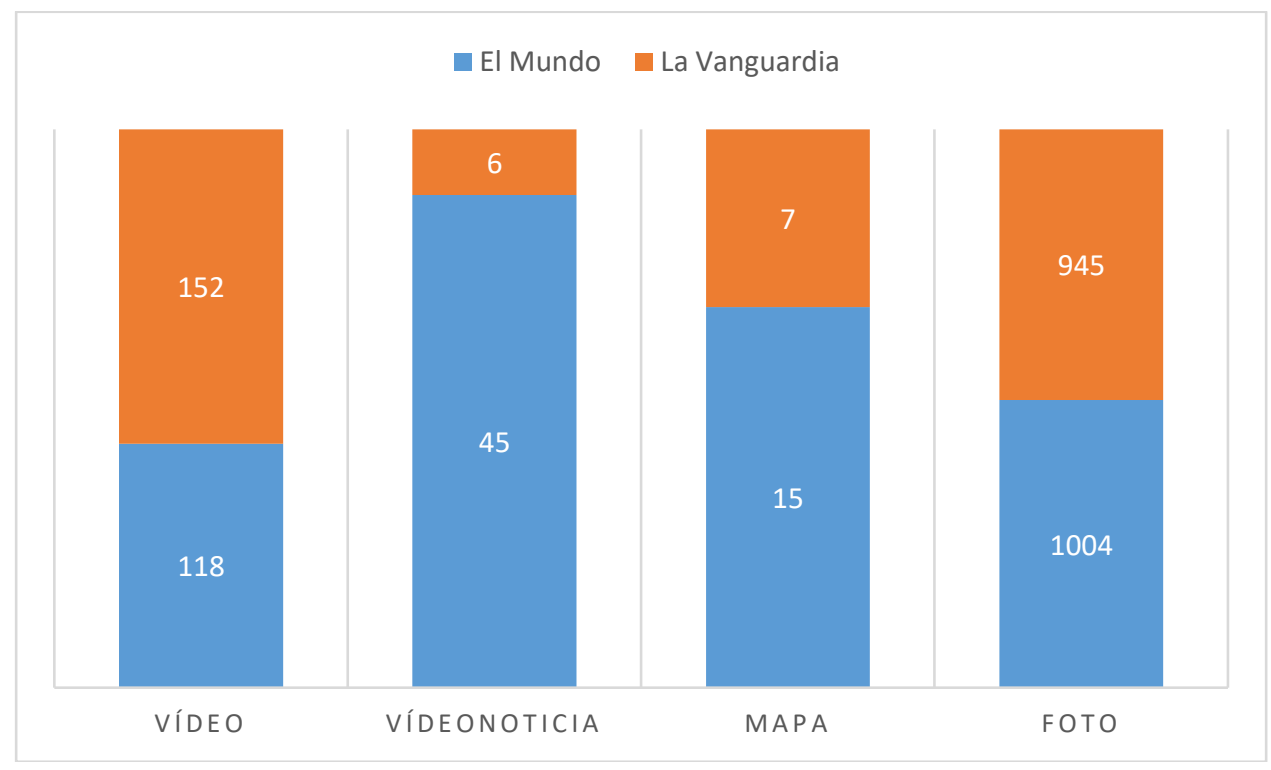

Gráfico 6. Elementos icónicos que acompañan a las noticias Fuente. elaboración propia

Respecto a la presencia de "vocablos-alarma", como los denomina Costa-Sánchez (2011:38), comentar que figuran en el 25,4\% de los titulares de El Mundo y en el 30,3\% de los de La Vanguardia, siendo más abundantes en las noticias de portada, lo cual indica que existe una intencionalidad de buscar un mayor impacto en la sensibilidad de los lectores.

En El Mundo, los cinco vocablos más utilizados (en el $69,3 \%$ de las ocasiones) han sido "muertos", "contagio", "confinamiento", "alarma" y "cuarentena", llegando a figurar 
en el $18,1 \%$ de los titulares. En el lado opuesto encontramos "apocalíptico", "alerta" y "amenaza", que aparecen en tan sólo 5 titulares.

"Confinamiento", "muertos", "contagio", "cuarentena" y "crisis" son los vocablosalarma más usados en La Vanguardia, de hecho, representan el $73,5 \%$ del total y figuran en el $22,7 \%$ de los titulares analizados. Por el contrario, "epidemia", "miedo" y "emergencia" son las palabras que con menor frecuencia aparecen, sólo en el 1,4\% de los titulares.

Respecto a los cintillos, a lo largo de nuestro análisis habíamos detectado un total de 1.009 en El Mundo, de los cuales sólo un 47,5\% hacen referencia al virus. De ellos, el $56 \%$ es la palabra "coronavirus" y el $22 \%$ "Covid-19". En menor medida figura el vocablo "crisis" (8\%), "pandemia" (4\%), y en un 3\% de las ocasiones "alarma" y "epidemia".

En La Vanguardia, de un total de 972 cintillos, el $82,6 \%$ es referente al virus. La palabra más abundante es "coronavirus" (30\%), seguido de "emergencia" $(22 \%)$ y "Covid-19" (18\%). En menor medida, se usa "crisis" (11\%) y en un $4 \%$ de las ocasiones las palabras "pandemia", "alarma" y "epidemia", términos que se emplean de forma indistinta, aunque comparten ciertos rasgos comunes como son la pérdida o amenaza de la vida.

A la vista de las cifras aportadas comprobamos que tanto los titulares como los cintillos de El Mundo resultan más informativos que los empleados por La Vanguardia, más alarmista al usar de forma recurrente la combinación "emergencia sanitaria", "crisis del coronavirus" o "crisis sanitaria".

Respecto a los antetítulos, el $70 \%$ de los 187 analizados en El Mundo y el $75 \%$ de los 119 de La Vanguardia contribuyen a espectacularizar la información incorporando términos considerados como generadores de inquietud en la población, tal es el caso de "crisis" y "alarma", que figuran en más de la mitad de los antetítulos analizados.

\subsection{Temática de los titulares}

En relación la temática, los titulares que hacen referencia al nivel de contagio, su evolución y al número de fallecidos a consecuencia del coronavirus representan el $25,5 \%$ del total en El Mundo. Le siguen, en orden de frecuencia, los relativos al confinamiento y la cuarentena $(16,6 \%)$, consecuencias económicas (13\%) y repercusiones sociales y culturales $(8 \%)$. Los mensajes de tranquilidad $(0,1 \%)$ y las altas médicas y mejoras (1\%) son, por el contrario, los temas menos usados por este diario.

Una línea similar encontramos entre los titulares de La Vanguardia. Los contagios y fallecimientos representan el $28,3 \%$ de los encabezamientos, le siguen los que hacen referencia al confinamiento (17,4\%), consecuencias económicas $(10,5 \%)$ y repercusiones sociales y culturales (8\%). Estos cinco temas ocupan el $64,2 \%$ de los 
titulares analizados. En el polo opuesto encontramos nuevamente los mensajes de tranquilidad, las entrevistas y las altas médicas y mejoras $(0,4 \%, 0,5 \%$ y $0,9 \%$, respectivamente).

Si relacionamos, el tamaño de los encabezamientos con la temática abordada, encontramos que los titulares de mayor impacto visual y que de forma prioritaria ocupan la portada y las portadillas de sección de El Mundo son aquellos que resaltan el número de contagiados y las muertes producidas por coronavirus (40,5\%), principalmente en España e Italia. Le siguen, los que remarcan las consecuencias negativas que el coronavirus está provocando en la economía (16\%) y aquellos relativos a las medidas de prevención y el confinamiento $(8,6 \%)$.

Por el contrario, aquellos dedicados a explicar el mecanismo de funcionamiento del virus $(1,8 \%)$, las altas médicas $(1,8 \%)$ o que transmiten mensajes de tranquilidad a la población $(0,6 \%)$ son minoritarios dentro de los de mayor impacto visual y en general.

En el caso de La Vanguardia, los titulares de portada que abordan los contagios y fallecidos en España suponen el 41,1\%. Le siguen los relativos al confinamiento y la cuarentena $(13,7 \%)$, las consecuencias económicas $(7,4 \%)$ y las comunicaciones oficiales $(7,4 \%)$. Por otra parte, los titulares dedicados a explicar el mecanismo de funcionamiento del virus, las altas médicas y los mensajes de tranquilidad a la población tan sólo representan un $3,4 \%$ del total.

\subsection{Valores noticiosos}

Los valores noticiosos son los factores o propiedades que convierten un hecho en noticia, es decir, los criterios que emplean los medios para seleccionar los hechos noticiables y para presentar periodísticamente las noticias (Díaz Rojo, 2009). En este sentido, resulta curioso reseñar que tanto El Mundo como La Vanguardia coinciden plenamente en los valores empleados y en el tono: la negatividad y la polémica.

El drama personal, el impacto social, el derrotismo y la controversia son los valores predominantes en el $69,2 \%$ de los titulares. Son numerosas las historias de contagiados y familiares de fallecidos narrados en primera persona, como el del actor de Gomorra, "encerrado con el cadáver de su hermana muerta por coronavirus" (El Mundo, 12/03); noticias que tratan de muertes, falta de material... "Italia. Locales cerrados, tanatorios desbordados, funerales prohibidos" (El Mundo, 12/04); y otras polémicas como las discrepancias manifiestas entre Gobierno y oposición 0 las burlas de los independentistas catalanes por los fallecimientos en Madrid: "El polémico tuit de Ponsatí sobre la crisis del coronavirus madrileña. 'De Madrid al cielo'" (La Vanguardia, 15/03).

El pesimismo también está presente en las noticias que hablan de las consecuencias que el coronavirus ha originado en todos los órdenes de nuestra vida: económicos, deportivos, laborales, sociales y culturales (23\%). "El coronavirus aboca a las aerolíneas a una de las peores crisis desde el 11-S" (El Mundo, 07/03), "La Feria de

Revista de Comunicación y Salud, 2020, Vol. 10, nº 2, pp. 503-524 
Abril también sucumbe al coronavirus: se suspende y podría celebrarse en septiembre" (El Mundo, 15/03).

De igual forma, la negatividad se deja sentir en titulares que hablan de la magnitud cualitativa y cuantitativa del virus, presente en todo el planeta: "El coronavirus deja ya mil muertos. Cronología de una curva que no se aplana" (La Vanguardia, 20/03), y que ha puesto en jaque al poder y a las naciones élites (10\%): "Trump tiene en la crisis del coronavirus su mayor obstáculo a la reelección" (La Vanguardia, 15/03).

Al tratarse de un virus desconocido, para el cual aún no hay tratamiento, la desesperanza impregna incluso las noticias que relatan hechos novedosos y que ocurren por primera vez, como es el confinamiento y los cierres de frontera entre países: "El Gobierno prepara el confinamiento de los españoles en sus casas salvo para ir a trabajar y urgencias" (El Mundo, 14/03); "El confinamiento alimenta la picaresca" (La Vanguardia 19/03).

Incluso las noticias relativas a actores, músicos o celebridades de distintas disciplinas suelen hacer mención a contagios o fallecimientos por el coronavirus $(1,6 \%)$ : "Tom Hanks mejora del coronavirus, aunque "no está muy bien", afirma su hermana" (EI Mundo, 19/03), "Lucía Bosé, madre de Miguel Bosé, fallece por el coronavirus" ( $\mathrm{La}$ Vanguardia, 23/03).

Por el contrario, los titulares que aluden a la positividad, valores educativos y utilidad no llegan al $6 \%$ del total. De hecho, las noticias con enunciados positivos, representan el $5,4 \%$ del total, y son aquellas relativas a las altas médicas, avances en la consecución de una vacuna, la labor realizada por el Ejército, o la rapidez con la que se montó el hospital de campaña en Madrid: "Vacuna del coronavirus: carrera de EEUU, china y Europa para frenar el virus... y la patente" (La Vanguardia, 18/03); "Madrid monta en tiempo récord el hospital más grande del mundo para el coronavirus, sólo superado por China" (El Mundo, 23/03).

Los aspectos curiosos o novedosos sólo figuran en el 1,7\% de los titulares, y siempre como factor determinante para despertar el interés: "La fauna recoloniza la ciudad ante el confinamiento por el coronavirus" (La Vanguardia, 24/03) o "La cuarentena limpia los canales de Venecia" (El Mundo, 18/03).

También son escasos los titulares que apuntan al entretenimiento $(1,8 \%)$ : "Guía completa de series de todas las plataformas para sobrellevar el confinamiento" ( $\mathrm{La}$ Vanguardia, 15/03); a la relevancia, es decir, a la forma en que la pandemia afecta de forma directa e inmediata a la vida de los lectores: "El coronavirus impone el teletrabajo a decenas de miles de trabajadores en 24 horas: Bancos, operadoras, constructoras, pymes..." (El Mundo, 11/03), o que con tono divulgativo aportan conocimientos científicos sobre el funcionamiento del virus (1,9\%): "Diferencias entre coronavirus y gripe común: síntomas, transmisión, letalidad..." (El Mundo, 24/03). 


\section{CONCLUSIONES}

El análisis de los titulares llevado a cabo indica que estamos sometidos a una gran sobreinformación sobre el coronavirus, sin embargo, ésta, en vez de ser constructiva y ayudar al lector a comprender el panorama complejo ante el que nos encontramos llega a provocar confusión y alarma.

El uso de vocablos desasosegantes como "crisis" o "emergencia" vaticinan un futuro incierto en el que será complicado no contagiarse y que la situación es cuanto menos desastrosa, a ello contribuye la redacción en tono negativo que emplean los titulares, más centrados en contagios, fallecimientos y repercusiones nefastas en ámbitos tan alejados de la salud como son el económico, cultural y deportivo.

Los titulares ayudan a estructurar la interpretación de los lectores sobre el texto completo del artículo, y si se toma en exclusiva la información aportada por los mismos como referencia de la actualidad estaremos antes una reconstrucción alarmista y sensacionalista de la misma, pues los titulares con mayor impacto visual y los que ocupan las portadas quedan lejos de transmitir mensajes de tranquilidad, sobre todo en La Vanguardia.

El valor noticioso de los titulares analizados está más que justificado, sin embargo, la vocación de servicio público se ve sustituida por un interés en llegar al mayor número de lectores utilizando el miedo y la inseguridad como señuelo y, en este sentido, son mayoritarias las malas noticias, de manera que los medios prefieren destacar los fracasos de la sanidad y de la investigación médica.

El valor predominante en los cuerpos de titulación es la polémica, un criterio de noticiabilidad presente en el número de contagios y fallecidos, en la ausencia de material preventivo básico y en la falta de unanimidad política para llevar a cabo medidas conjuntas.

Aunque, en menor medida, apenas llega al $11 \%$ del total, la esperanza y las buenas noticias también tienen cabida en los titulares, sobre todo aquellos que relatan la solidaridad de la gente, las donaciones de las empresas, los esfuerzos desmedidos que realiza la comunidad sanitaria y el magnífico trabajo realizado por el Ejército y los cuerpos de Seguridad del Estado.

A pesar de que el presente estudio confirma las hipótesis de partida y los objetivos marcados en nuestra investigación, estamos obligados tener en cuenta algunas limitaciones potenciales del mismo a la hora de interpretar los resultados. Primero, aunque el análisis de los titulares ofrece datos importantes, hemos de tener presente que como afirman Bleich et al. (2015): "pese a que los titulares ayudan a estructurar la interpretación de los lectores sobre el texto completo del artículo, no lo determinan".

De igual forma, sería interesante realizar un estudio posterior para ver si los resultados obtenidos se mantienen en el tiempo o, si una vez, pasado el pico de 
contagios y fallecimientos y en la desescalada del confinamiento, los medios optan por alejarse del sensacionalismo y abogan por un mensaje más tranquilizador y divulgativo, a la vez que formativo.

\section{REFERENCIAS}

AIMC (2019). Estudio AIMC Q Panel Diarios y suplementos-2019. Recuperado de https://www.aimc.es/otros-estudios-trabajos/aimc-q-panel/diarios-suplementosasociados/

AMI (2017). Libro blanco de la Información. Madrid: Asociación de Medios de Información.

Alonso-González, M. (2018): La comunicación científica en la prensa digital española: radiografía de sus fuentes informativas. Communication Papers, 7(13), 9-26. doi: $\underline{10.33115 / \text { udg bib/cp.v7i13.21984 }}$

Amoedo, A. (2019). Digital News Report. Reuters. Recuperado de http://www.digitalnewsreport.es/2019/los-algoritmos-influyen-tanto-como-la-marca-delos-medios-para-llegar-a-las-noticias-en-internet/

Armentia Vizuete, J. I. y Caminos Marcet, J. M. (2009). Redacción informativa en prensa. Barcelona: Ariel Comunicación.

Barrio, I., González, J., Padín, L., PeraL, P., Sánchez, I. y Tarín, E. (2012). Modelos de Investigación Educativa. Madrid: Universidad Autónoma

Benaissa, S. (2019). Medios impresos versus digitales: de la lectura agónica de periódicos a los nuevos consumos de información digital. El argonauta español, 16. doi: $\underline{10.4000 / \text { argonauta.3855 }}$

Bleich, E.; Stonebraker, H.; Nisar, H. y Abdelhamid, R. (2015). Media Portrayals of Minorities: Muslims in British Newspaper Headlines, 2001-2012. Journal of Etnic and Migration Studies, 41(6), 942-962. doi: $\underline{\text { 10.1080/1369183X.2014.1002200 }}$

Costa-Sánchez, C. (2011). Tratamiento informativo de una crisis de salud pública: Los titulares sobre gripe A en la prensa española. Revista de Comunicación de la SEECl, 25, 29-42. doi: 10.15198/seeci.2011.25.29-42

Cué, C. (19 abril, 2020). El Gobierno dejará salir a los niños desde el 27 de abril y hará una desescalada paulatina por zonas. El País. Recuperado de https://elpais.com/espana/2020-04-18/el-gobierno-dejara-salir-a-los-ninos-desde-el27-y-hara-una-desescalada-paulatina-por-zonas.html 
Díaz Rojo, J. A. (2009). La polémica, las "buenas noticias" y las "malas noticias" como valores noticiosos predominantes en el discurso sobre la salud en tres diarios nacionales españoles. Tonos, Revista electrónica de Estudios Filológicos, 17. Recuperado de https://www.um.es/tonosdigital/znum17/secciones/estudios-4malasnoticias.htm

Fernández Gil, J.R (2010). Fuentes de análisis para el estudio de la prensa diaria. Anales de Documentación, 13, 135-158. Recuperado de https://revistas.um.es/analesdoc/article/view/107101

Fontcuberta, M.d.M. (1996). La noticia. Pistas para percibir El Mundo. Barcelona: Bosch.

Hassan, Y. (1 noviembre, 2002). Introducción a la Usabilidad. [Mensaje en un blog] Recuperado http://www.nosolousabilidad.com/articulos/introduccion usabilidad.htm

Imbert, G. (1999). La hipervisibilidad moderna: el nuevo mito televisivo. En La hipervisibilidad televisiva: Nuevos imaginarios / nuevos rituales comunicativos. Madrid: Universidad Carlos III, 1999. Recuperado de http://turan.uc3m.es/uc3m/inst/MU/Imbert4.htm

INE (28 enero, 2020). Encuesta de población activa. EPA. Cuarto trimestre 2019. Recuperado de en :https://www.ine.es/dyngs/INEbase/es/operacion.htm?c=Estadistica C\&cid=1254736 $\underline{176918 \& \text { menu=ultiDatos\&idp }=1254735976595}$

MSCBS (26 marzo, 2020). Enfermedad por coronavirus, Covid-19. Información científica-técnica. Centro de Coordinación de Alertas y Emergencias Sanitarias. Secretaría General de Sanidad y Consumo. Ministerio de Sanidad. Recuperado de https://www.mscbs.gob.es/profesionales/saludPublica/ccayes/alertasActual/nCovChina/documentos/20200326 ITCoronavirus.pdf

La Vanguardia (10 abril, 2020). La Vanguardia, líder en Cataluña y tercero en España. La Vanguardia. Recuperado de https://www.lavanguardia.com/vida/20190410/461574046748/la-vanguardia-egmabril.html

Lafraya, C. (14 marzo, 2020). El teletrabajo se impone en las empresas: respuesta rápida para atajar al coronavirus. La Vanguardia. Recuperado de https://www.lavanguardia.com/economia/20200314/474114767539/coronavirusteletrabajo-espana-covid-19.html

López, X. y Túñez, M. (1995). Redacción en prensa: La noticia. Santiago de Compostela: Lea. 
Mediavilla, K. (4 mayo, 2010). Titulares interpretativos. Comunicación y Política. [Mensaje en un blog] Recuperado de http://koldomediavilla.blogspot.com/2010/05/titulares-interpretativoscomunicacion.html

Navas, M. E. (30 marzo, 2020). Un enemigo increíblemente astuto: por qué el virus que causa del Covid-19 se propaga con tanta eficacia entre los humanos. BBC. Recuperado de https://www.bbc.com/mundo/noticias-52069525

Núñez Ladeveze, L. (1991). Manual para periodismo. Madrid: Ariel.

OMS (13 marzo, 2020). Coronavirus disease 2019 (Covid 19). Situation Report, 53. Recuperado de https://www.who.int/docs/default-source/coronaviruse/situationreports/20200313-sitrep-53-covid-19.pdf?sfvrsn=adb3f72 2

Reglamento sanitario internacional. Recuperado de https://www.who.int/ihr/revisionprocess/revision/es/

Oliva Marañón, C. (2011). Análisis lingüístico de los titulares de prensa en internet. En Un nuevo léxico en la red. (pp.53-69). Sevilla: Dykinson.

Peña, D. (28 marzo, 2020). Estos son los 12,6 millones de personas que han seguido trabajando durante el confinamiento. Nius. Recuperado de https://www.niusdiario.es/economia/empleo/coronavirus-estado-alarma-quien-trabajacasi-trece-millones-personas-por-sectores 18 2921370322.html

PRNoticias (30 diciembre, 2019). ¿Cuál es el balance de la prensa digital en 2019 según comScore? PRNoticias. Recuperado de https://prnoticias.com/prensa/prensapr/20176790-comscore-balance-periodicos-online

Pou Amérigo, M. J. (2000). Los titulares de prensa y los nuevos servicios de información por correo electrónico y teléfono móvil. Comunicación, 7. Recuperado de en https://webs.ucm.es/info/emp/Numer 07/7-4-Comu/7-4-07.htm

RTVE (30 enero, 2020). La OMS declara la emergencia internacional por el coronavirus de Wuhan. RTVE. Recuperado de https://www.rtve.es/noticias/20200130/omsdeclara-emergencia-internacional-coronavirus-wuhan/1997920.shtml

Ruiz Acosta, M. J. (1992). Los titulares en prensa: estudio de su evolución y lenguaje. Lenguaje informativo y filmográfico, pp. 79-84. Recuperado de https://idus.us.es/bitstream/handle/11441/40151/pliegos1 7.pdf? sequence=1\&isAllow $\underline{e d=y}$

Thomas, G. (2011). A typology for the case study in social science following a review of definition, discourse and structure. Qualitative Inquiry, 17(6), 511-521. doi: $\underline{10.1177 / 1077800411409884}$ 
Zorrilla, Barroso, J. M. (2002). El titular de la noticia: estudio de los titulares informativos en los diarios de difusión nacional (Tesis Doctoral, Universidad Complutense de Madrid). Recuperado de https://eprints.ucm.es/1865/

\section{AUTORA}

\section{Marián Alonso-González}

Marián Alonso González es Doctora en Comunicación por la Universidad de Sevilla (2008) con una Tesis Doctoral que versa sobre el cambio tecnológico de $A B C$ de Sevilla. Miembro de la Asamblea de Mujeres Periodistas de Sevilla y del Censo de Expertas, compagina su labor profesional como Técnico de Comunicación en Adif con su labor docente como profesora asociada en la Facultad de Comunicación de Sevilla, donde imparte clases de nuevas tecnologías y redacción. Especializada en redes sociales, ha orientado su investigación a campos relacionados con la Comunicación 2.0, el Periodismo 3.0, las audiencias sociales y los nuevos lenguajes multimedia e interactivos.

Orcid ID: https://orcid.org/0000-0003-2676-0449

Google Scholar: https://scholar.google.com/citations?user=pTW9yp0AAAAJ\&hl=es

ResearchID: https://www.researchgate.net/profile/Alonso Marian 